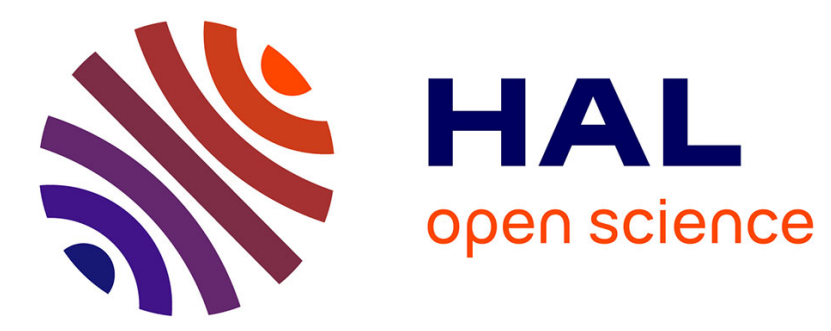

\title{
Focus \& Clause Structuration in the Minimalist Program
}

\author{
Aritz Irurtzun
}

\section{To cite this version:}

Aritz Irurtzun. Focus \& Clause Structuration in the Minimalist Program. 2005. artxibo-00000022

HAL Id: artxibo-00000022

https://artxiker.ccsd.cnrs.fr/artxibo-00000022

Submitted on 11 Oct 2005

HAL is a multi-disciplinary open access archive for the deposit and dissemination of scientific research documents, whether they are published or not. The documents may come from teaching and research institutions in France or abroad, or from public or private research centers.
L'archive ouverte pluridisciplinaire HAL, est destinée au dépôt et à la diffusion de documents scientifiques de niveau recherche, publiés ou non, émanant des établissements d'enseignement et de recherche français ou étrangers, des laboratoires publics ou privés. 


\title{
Focus and Clause Structuration in the Minimalist Program
}

\author{
Aritz Irurtzun \\ EHU-U. Basque Country \& HiTT \\ <fvbirsva@vc.ehu.es>
}

\begin{abstract}
This article explores the possibility that the derivation of focus from syntax to LF can be implemented in a direct and transparent way. Assuming the principles of Bare Phrase Structure, I develop a derivational construal of the focus structure and provide a syntax of focus in Basque combining it with an eventish logical form whereby the focus falls in the scope of a binary existential quantifier ( $c f$. Herburger (2000)). Adopting recent ideas of Hornstein \& Uriagereka (2002), this transparent interface is accomplished by allowing binary quantifiers to reproject at LF to get their nuclear scope.
\end{abstract}

\section{1-Introduction: ${ }^{1}$}

The analysis of 'focus' has always been problematic for any model of generative grammar that tries to account for the properties of I-languages abstracting away from external use of page and discourse factors. The following passage from Chomsky (1995b: 220) at E problematic nature of focus:

Notice that I am sweeping under the rug questions of considerable significance, notably, questions about what in the earlier Extended Standard Theory (EST) framework were called 'surface effects' on the interpretation. These are manifold, involving topic-focus and theme-rheme structures, figure ground properties, effects of adjacency and linearity and many others.

In this paper, I analyze the place of focus in the general architecture of the grammar from a minimalist perspective and how the insertion of focus affects the syntax and semantics of a sentence. In Section 2 I review the main approaches to the syntax of focus (the 'Left Periphery' one and the 'NSR-based' one) discussing their main imports and shortcomings. In Section 3, I present an alternative to the previous approaches by combining the derivational approach to focus structure of Irurtzun (2003) and the neo-Davidsonian semantic representation at logical form of Herburger (2000). In Section 4, I apply the proposal of Section 3 to Basque, a language that shows some effects of focalization in overt syntax, and provide a syntax for the semantics of focus, adapting the predicate analysis of quantifiers of Larson (1991) and the reprojection mechanism of Hornstein \& Uriagereka (2002). A summarizing and concluding Section follows.

\footnotetext{
1 This research was supported by the grants BFF2002-04238-C02-01 of MCYT-FEDER, UPV-EHU 9 UPV 00114.130-160.09-2004 U of EHU-U. Basque Country and a predoctoral research grant by the Basque Government. I want to thank Juan Uriagereka, Elena Herburger, Gorka Elordieta, Javier Ormazabal, Myriam UribeEtxebarria, Richard Larson, Utpal Lahiri, Milan Rezac, Melanie Jouitteau, Urtzi Etxeberria, Maia Duguine, Susana Huidobro and Ángel J. Gallego for comments and helpful discussion. Usual disclaimers apply.
} 


\section{2-Left Peripheric \& NSR-based theories of Focus}

In recent years, two main syntactic approaches have been developed to account for the syntactic effects of focus; I will call these the 'Left Peripheric' approach (grouping works like Brody (1990), Ortiz de Urbina (1995) and Rizzi (1997)) and the 'Nuclear Stress Rule-based' approach (henceforth 'NSR-based' approach, grouping works like Neeleman \& Reinhart (1998), Zubizarreta (1998) and Arregi (2003)). Next, I will summarize the main advantages and shortcomings of each of these approaches.

\subsection{The 'Left Peripheric' Approach:}

The 'Left Peripheric' approach starts out from the observation that in some languages, focus affects the syntactic configuration of the clause by appearing at the left periphery. This includes languages like Basque in which the focus phrase appears in the immediately preverbal position:
(1)
a. Broad Focus: Urtzik bokata jaten du
Urtzi sandwich eat AUX
"Urtzi eats the sandwich"
b. Narrow Focus: [Urtzik] jaten du bokata
Urtzi eat AUX sandwich
"[Urtzi $]_{\mathrm{F}}$ eats the sandwich"

In order to account for these dislocations, in this type of approaches it is posited that a functional head (be it $\mathrm{C}^{\mathrm{o}}, \mathrm{Foc}^{\mathrm{o}}, \mathrm{F}^{\mathrm{o}}$ or any other) attracts the focalized element to its specifier and that the verb raises to its head to check the $[+\mathrm{F}]$ feature against the focal $\mathrm{XP}$ in a local relation. Thus, the $[+\mathrm{F}]$ feature of the focalized XP is checked in a SpecHead relation observing a "Focus Criterion" (Horvath (1995), Ortiz de Urbina (1995)), as shown in (2):

(2)

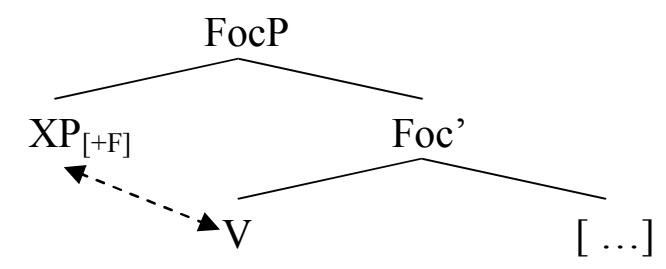

This head could be immersed in a series of heads encoding different discourse notions as in L. Rizzi’s (1997) cartography of the left periphery:

(3) Force .... (Topic) ... (Focus) ... Fin ... IP

This analysis of the surface configuration by the postulation of syntactically triggered movements accounts in a very straightforward way for some of the restrictions that focalization observes in these languages. These are Weak Crossover and island effects, pied-piping phenomena, the behavior of long distance movements, etc.

There are many subtleties involved in this approach, but I will leave their discussion for Section 4, where I discuss Basque data that shows the presence of a left peripheric head triggering focus movements. There, I will adopt a version of this approach to analyze Basque focalization in detail. Here, I just want to observe one of 
the shortcomings of the left peripheric approach: despite the fact that it might explain very comprehensively the syntactic transformations that a focalized XP might trigger in a clause, there is no explanation of how it is that this XP is focused. In other words, under this approach, we have to assume that a given XP is focused without any explanation of how it gets its focal status in the way from the numeration to spell out.

\subsection{The 'NSR-based' Approach:}

In contrast to the 'Left Peripheric' approach, the NSR-based approach has a more explanatory aim regarding the issue of how a given XP is focused in a given sentence.

This approach starts out from the observation that Nuclear Stress (henceforth $N S$ ) apparently falls on different positions in different languages. ${ }^{2}$ As seen in the out-ofthe-blue sentences in $(4 a-b)$ :

(4) a. ENGLISH: Jesus preached to the people of JUDEA.

b. BASQUE: Jesusek JUDEAKO jendeari predikatu zion.

Jesus Judea-of people-to preached AUX

In order to capture this asymmetry, Halle \& Vergnaud (1987) proposed a parametrically variable Nuclear Stress Rule (NSR). They postulated different parametric settings of the rule for typologically different languages like Basque and English. Departing from this parametric NSR, Cinque (1993) shows that the surface differences in NS placement observed in both types of languages could be very easily derived from deeper differences between them: namely, the Head Parameter. Whereas English is a Head-First language, Basque has been analyzed as being Head-Last ( $c f$. among others Arregi (2003a, 2005)). ${ }^{3}$ Therefore, Cinque (1993) proposes a much more principled $N S R$ to account for the (lack of) variability in NS assignment:

(5) Nuclear Stress Rule (Cinque (1993)):

a. Interpret boundaries of syntactic constituents as metrical boundaries.

b. Locate the heads of line $N$ constituents on line $N+1$.

c. Each rule applies to a maximal string containing no internal boundaries.

d. An asterisk on line $N$ must correspond to an asterisk on line $N+1$.

\footnotetext{
${ }^{2}$ The NS is basically the 'main' stress of a sentence, and it has been observed to have a range of special properties when compared to other accents in an utterance in different languages (a different pitch shape, increased fundamental frequency (F0) values, strict alignment with the accented syllable...). This relative prominence and alignment differences are misterious for the Autosegmental-Metrical theory of intonation since, in principle, and giving the postulates of this theory, there is no reason for the NS to behave in a different way than any other accent having the same label or internal structure. But, apparently, it does. It could be argued that ' $N S$ ' is more a taxonomic or observational notion than a theoretical primitive, but I think that the evidence for treating these pitch accents as categorically different entities from the rest of the pitch accents is convincing, whatever this means.

${ }^{3}$ This is, however, a very controversial and open issue (cf. Hualde \& Ortiz de Urbina (2003) for an extensive presentation of Basque data and Artiagoitia (2000) for a nice review of the literature).
} 
This NSR will blindly assign grid marks to XPs and according to it, the deeper an element is in the syntactic structure, the deeper it will end up in the metrical grid. The derivation of the $N S$ placement will be straightforward: the element with most grid marks will get the NS in an out-of-the-blue context:

(6) a. Jesus preached to the people of JUDEA.

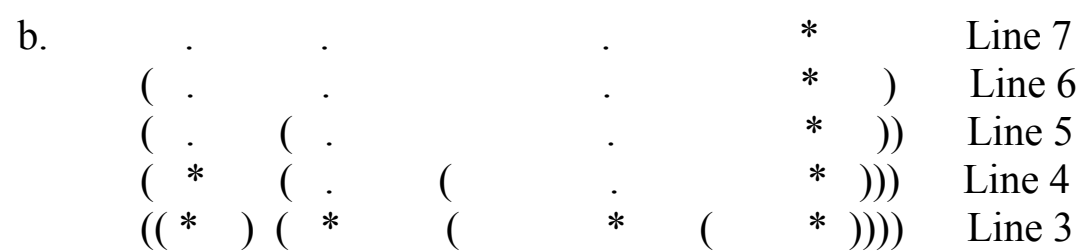

[Jesus] [preached [to the [people [of Judea]]]]

According to the NSR in (5), the different surface locations of the NS in English and Basque would follow from differences in their syntax, not from any differences in their phonology; basically, the head parameter setting difference will derive in a different metrical grid for each language:
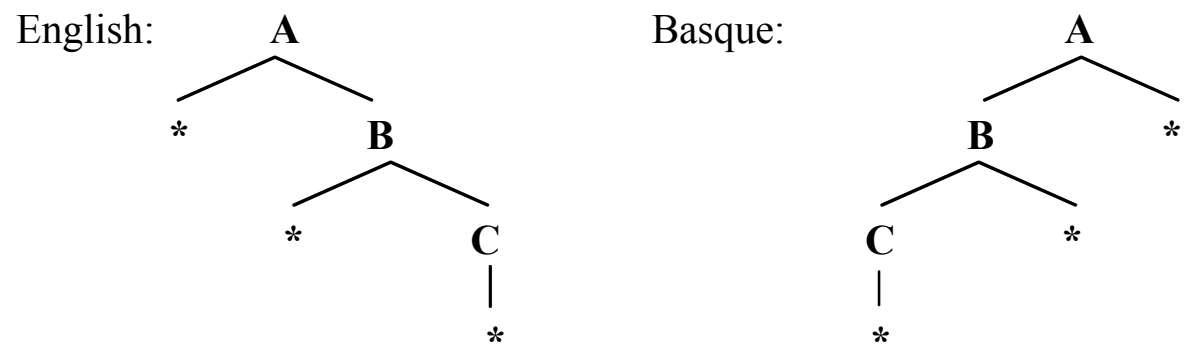

This basic NSR that assigns NS to the most embedded element in any clause predicts the facts correctly in out-of-the-blue contexts, since it is claimed that the focus marking on the element that gets the NS might project higher up, up to the matrix node (the entire clause). This is accomplished by the postulation of another principle: a "focus to accent constraint" that assigns focus to the element that dominates the element bearing the NS. For instance, the sentence in (8) with NS on the object "Mary" would have an ambiguous Focus-Structure (F-Structure), or what Neeleman \& Reinhart (1998) call a "Focus Set" (a set of the potential foci given a certain NS placement from which discourse -not grammar- will pick up the "actual" focus of the sentence):

$$
\left[\left[\left[\text { John }\left[\text { kissed }[\text { MARY }]_{\mathrm{F}}\right]_{\mathrm{F}}\right]_{\mathrm{F} .} \quad(\text { Focus Set }=\{\mathrm{IP}, \mathrm{VP}, \mathrm{Obj}\})\right.\right.
$$

However, it is not always the case that the most embedded element (or any of the nodes that dominate it) is the focus of the sentence. Therefore, another postulated principle comes at play whenever we want to derive focus marking on a different XP: the "accent to focus constraint"; a principle whereby the focus has to bear the NS at the end of the derivation. Thus, if the element that is focused is not the most embedded one or any element dominating it, some marked operations will have to take place. These operations can be of two types: (i) marked stress assignments to 'the element that is to be focused' or (ii) 'stress-avoiding movements' of the most embedded element so that 'the element that is to be focused' ends up as the most embedded one in the structure, and thus it gets the NS via the NSR. With the application of these marked operations we circumvent a violation of the "accent to focus constraint". This is, basically, the 
proposal in Neeleman \& Reinhart (1998) for English in (9) and Dutch in (10), English adopting the 'stress shifting' operations (9b) while Dutch adopts the 'scrambling' ones (10b):

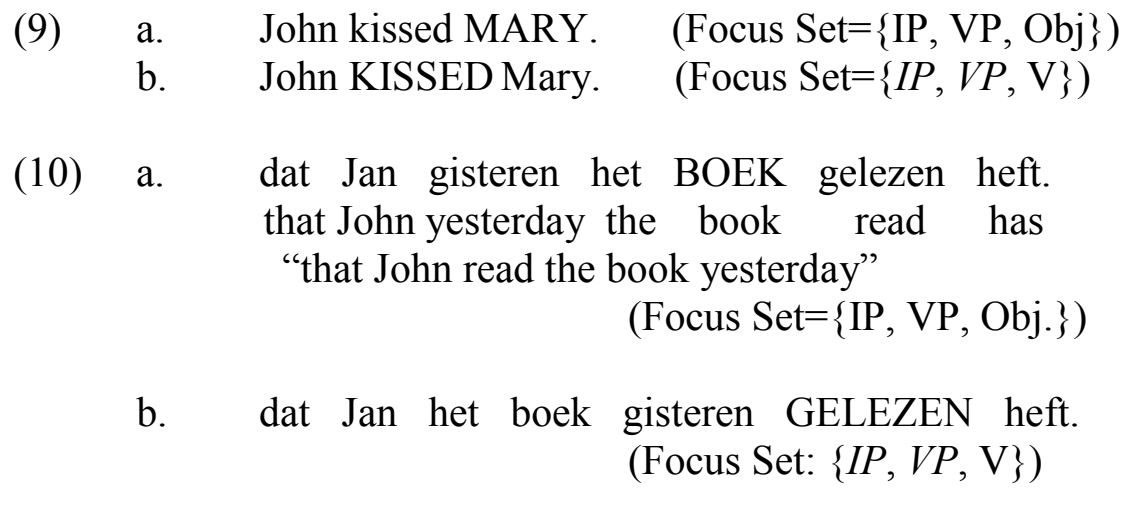

Finally, an economy principle will ban the choice of VP or IP from the focus sets of the (b) examples, since these potential foci were already available through an automatic 'projection of focus' if the direct object was the accented element, and without having to recur to the marked 'stress shift' or 'scrambling' operations. Thus, the actual focus in both (b) sentences will be the verb.

I won't discuss these issues now but I will just note here that there are some empirical and conceptual inadequacies in this theory of F-Structure. For instance, in many languages categorically different pitch accents are used to convey broad vs. narrow foci, which shows that the F-Structure of a sentence is not ambiguous (hence, the focus set does not exist computationally). Likewise, it has been observed for many languages that the 'actual' focus induces a specific prosodic phrasing in surface phonology (so, what the actual focus is has to be available for the phonological component). Furthermore, the 'stress avoiding' movements are instances of global look ahead operations that are at odds with the core minimalist assumptions ( $c f$. Irurtzun (2003) for details and further discussion). I will leave these issues here and after presenting my alternative to these approaches, I will resume to the discussion of the $N S R$-based theory (and some of its shortcomings when it comes to Basque data).

\section{$\underline{\text { 3-Focus Structure and Interpretation }}$}

In this Section I present a syntactic theory of F-Structure construal and its semantic interpretation, combining some of the postulates of the minimalist program in syntax, with an internalist Neodavidsonian semantics. First, I present my analysis of the derivation of the focus structure in narrow syntax and then, I adapt it to the logical form representation of focus proposed by Herburger (2000).

\section{$\underline{3.1 \text { Derivational Approach to the Focus Structure }}$}

Given the inadequacies of PF approaches to derive the focus structure, I will adopt a derivational approach to focus structure as proposed in Irurtzun (2003). According to this theory, the $[+\mathrm{F}]$ feature is an optional formal feature and it is potentially assigned to several tokens of the numeration. The focus structure, instead of being 'projected' at PF, is constructed derivationally by means of Merge. In other words, when an element $\alpha$ and an element $\beta$ undergo Merge, both of them bearing the $[+\mathrm{F}]$ feature, a new syntactic object will be created that in "Bare Phrase Structure" terms 
(cf. Chomsky (1995a)), will be a set-theoretic object containing only [+F] featured lexical items:

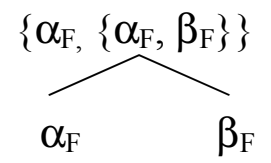

In that way, when a syntactic object/set of $[+\mathrm{F}]$ featured lexical items is merged with an element that does not bear the $[+\mathrm{F}]$ feature itself, the new syntactic/set-theoretic object will not be a set of containing only $[+\mathrm{F}]$ featured elements, as the highest phrase in (12) shows:

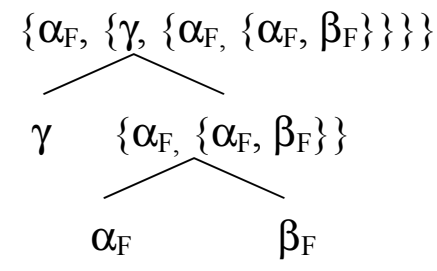

Although the head (and label) of the structure in (12) is marked as [+F], the whole structure won't be a set containing only $[+F]$ featured lexical items, since the element $\gamma$ (a member of $\left\{\gamma,\left\{\alpha_{\mathrm{F}},\left\{\alpha_{\mathrm{F}}, \beta_{\mathrm{F}}\right\}\right\}\right\}$ ) does not bear the [+F] feature itself. Precisely because of the lack of the $[+F]$ feature of $\gamma$, in this structure we will have just $\left\{\alpha_{F},\left\{\alpha_{F}\right.\right.$, $\left.\left.\beta_{\mathrm{F}}\right\}\right\}$ as focus. Thus, we keep a direct mapping between syntax and semantics and build semantic interpretation in a strict compositional way, and observing one of the core minimalist assumptions: the "Inclusiveness Condition" (Chomsky (1995b: 228))):

Any structure formed by the computation (in particular, $\pi$ and $\lambda$ ) is constituted of elements already present in the lexical items selected for $\mathrm{N}$; no new objects are added in the course of computation apart from rearrangements of lexical properties...

Thus, depending on which lexical items enter into the derivation bearing the $[+\mathrm{F}]$ feature, we will have different F-Structure possibilities within a DP: ${ }^{4}$
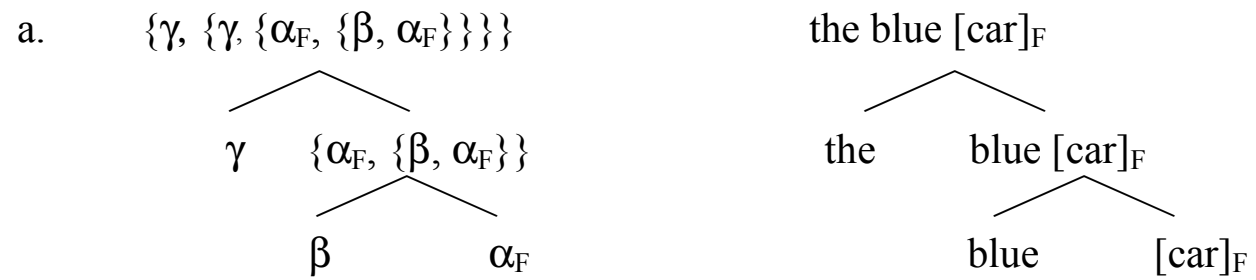

\footnotetext{
${ }^{4}$ Only some of the possibilities are represented, and all three are structures where the $[+\mathrm{F}]$ featured lexical items that enter into the derivation are merged with each other. There are other possibilities though, and among them, cases where for instance just a Det and a Noun enter the derivation bearing the $[+F]$ feature but the lexical items don't merge together (the same with a subject and object, and so on). These are more complex constructions involving answers to multiple questions and split focalizations ( $c f$. Irurtzun (2005b) for an analysis these constructions).
} 
b.

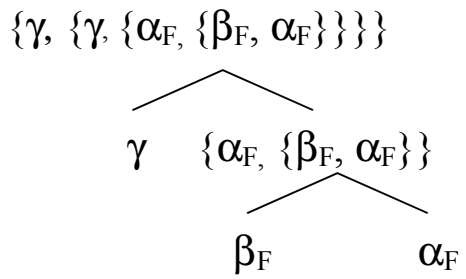

c.

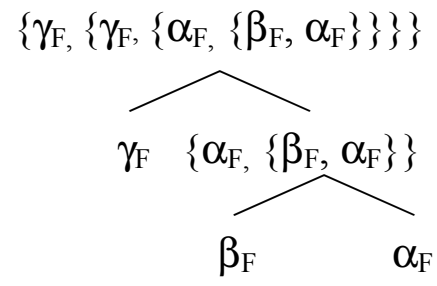

the $[\text { blue car }]_{\mathrm{F}}$

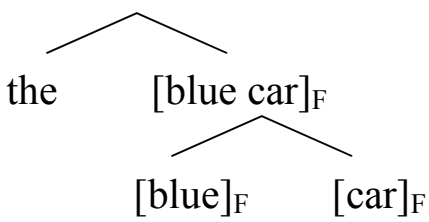

[the blue car $]_{\mathrm{F}}$<smiles>CCC</smiles>

$[\text { the }]_{\mathrm{F}} \quad[\text { blue car }]_{\mathrm{F}}$

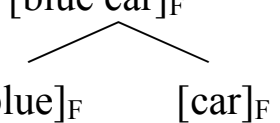

The adoption of this system allows us to construct the different F-structure possibilities depending directly on the elements selected for the numeration and, at the same time, it fixes the F-Structure already in the narrow syntax. Thus, the focus can have effects at both interface levels (PF and LF). ${ }^{5}$ Furthermore, it explains some of the problematic data for PF theories of focus projection from heads to phrases (e.g. Selkirk (1995)). For instance, the impossibility of having a QP focus when the Q bears the NS (i.e., the impossibility of projecting from Q to QP). For example, in (14), with the universal quantifier 'all' bearing the $N S$, the reading where the whole QP is focused is unavailable, and the only possible reading is the one where only the $\mathrm{Q}$ is focused: ${ }^{6}$

$$
\left[[\mathrm{ALL}]_{\mathrm{F}} \text { the girls }\right] \text { sang a song. } \quad v s . \quad *[[\mathrm{ALL}] \text { the girls }]_{\mathrm{F}} \text { sang a song. }
$$

As just mentioned, this derivational system of F-Structure construction will predict automatically the size (and at LF, the semantic import) of focus in a strict and compositional way: basically, it will be a direct product of the numeration (which elements enter into the derivation bearing the $[+\mathrm{F}]$ feature) and the syntactic derivation from it (phrase marker construction via merge). Therefore, this derivational analysis of the focus structure as a rearrangement of the lexical properties of the items of the numeration, combined with the neo-Davidsonian semantics to be introduced in the next Section, should be regarded as an attempt towards an internalist exploration of the knowledge of meaning; one that "could be considered syntax in the technical sense" (Chomsky (2000a: 174)).

\footnotetext{
${ }^{5}$ Observe that, having the F-Structure already set in the narrow syntax, there will be no trouble in PF since the NSR can be sensitive to the F-Structure. The phonological component will assign the NS to the most prominent element within focus, that is (the element with most grid marks following Cinque (1993)) and apply the appropriate focus-affected phonological phrasing. See Irurtzun (2003) for more on this.

${ }^{6}$ There are some additional interesting issues concerning this type of data since in an out-of-the-blue context a sentence like (14) can have both a distributive or collective reading, whereas in a context where the universal quantifier is focalized the only available reading is the distributive one (cf. Irurtzun \& Etxeberria (2004)). Recall that even though I won't be adopting this model here, to be able to predict the semantic import of focus is a necessary condition for the 'Alternative Semantics' approach of focus semantics (Rooth $(1985,1992)$ ). According the Alternative Semantics, the semantic contribution of focus is to add to the 'Ordinary Semantic Value' (the proposition that the sentence denotes) an additional 'Focus Semantic Value' constituted by alternative propositions obtained by the substitution of the focused phrase with alternatives available in the discourse that match the focus in semantic type.
} 


\subsection{Semantics of Focus}

In order to provide a semantics to the focus phrase, I will adopt the "eventish" proposal of Herburger (2000). She presents a theory of focus interpretation based in the event semantics approach first proposed by Davidson (1967) and later developed by Parsons (1991) and Schein (1993) among others.

The basic idea of the proposal is to take a proposition to be a description of an event, verbal arguments and adjuncts to be predicates of the event and the focus to fall in the scope of a restricted existential quantification over the event. Thus, the sentence in (15a) will have the logical form in (15b), where the non-focused chunk is the restrictor of the existential quantification (i.e., the sentence's 'aboutness') and the focus is in the scope (cf. Herburger $(1998,2000))$ :

$$
\begin{aligned}
& \text { a. } \quad \text { Milan bought }[\text { CIDER }]_{F} \text {. } \\
& \text { b. } \quad[\exists \text { e: } \operatorname{Agent}(e, \text { milan }) \& \operatorname{Buy}(e) \& \operatorname{Past}(e)] \text { Theme(e, cider })
\end{aligned}
$$

This semantic representation captures in a very neat way the semantic relation between the focus and the rest of the sentence since there will be no need to add any 'novelty of information' or 'not given information' notion to the focus as a primitive; the novelty of the focus will be its relation to the rest of the sentence (the restrictor of the existential quantification). This relative novelty is much more accurate than the absolute novelty for focus proposed in many of the works dealing with focus as 'new information' vs. 'old information' since, as can be seen in the question/answer pair in $(16 a-b)$, the actual focus of the sentence doesn't have to be absolutely new or non-given in the discourse (ex. from Rooth 1996: 271):

(16) a. Does Ede want tea or coffee?

b. Ede wants [COFFEE $]_{\mathrm{F}}$

c. $\quad[\exists e: \operatorname{Agent}(\mathrm{e}, \mathrm{ede}) \& \operatorname{Want}(\mathrm{e}) \& \operatorname{Present}(\mathrm{e})]$ Theme(e, coffee $)$

The focus of (16b) is not absolute new information in the discourse but relative new information in the proposition: relative to the non-focused part and contrasting with the other alternative in the discourse, 'tea', that in this dialogue is explicit but might not be so.

However, according to Herburger, and since focus has non-local effects, it won't be enough to have the $[+\mathrm{F}]$ featured material in the scope; otherwise we wouldn't be able to capture some of the possible meanings of the sentence like (17) (ex. 57 of Herburger (2000)):

(17) [ $\mathrm{CP}_{1}$ Mary told me about [DP the rumor [ $\mathrm{CP}_{2}$ that Bill had said [ $\mathrm{CP}$ that SUE was going to India].

According to the judgments in Herburger (2000), the sentence in (17) can have at least the following three readings:

(18) a. "Mary told me about the rumor that Bill said that it was SUE who was going to India”.

b. "Mary told me about the rumor that it was SUE who was such that Bill had said that she was going to India" 
c. "It was SUE who was such that Mary told me about the rumor that Bill had said that she was going to India"

For instance, the reading in $(18 \mathrm{~b})$ is obtained by having the focus affecting the event denoted by the verb 'say' in $\mathrm{CP}_{2}$ and the one in (18c) is one where the focus affects the event of the $\mathrm{CP}_{1}$. Given these non-local effects of focus, at the scope of the event quantifier we cannot have just the focused phrase but the entire sentence. Thus, the specific import of focus will be just not being present in the restriction of the existential quantifier; that is, not being present in the sentence's 'aboutness' ( $c f$. Irurtzun (2005c) for a reformulation of these ideas in terms of Russellian definite descriptions).

Assuming this basic LF representation for sentences and the derivational FStructure construal presented in Section 3.1, we can now account for the semantic import of the focus phrase in a very straightforward, bottom-up fashion. The sentence in (19a) as an answer to the question in (19b) will have the logical form in (19c), derived as in (19d) (tense is omitted for simplicity): ${ }^{7}$

(19) a. Milan [bought cider $]_{\mathrm{F}}$

b. What did Milan do?

c. $\quad[\exists e: \operatorname{Agent}(\mathrm{e}$, milan) $]$ Theme(e, cider $) \& \operatorname{Agent}(\mathrm{e}$, milan $) \&$

$\operatorname{Buy}(\mathrm{e})$

d.

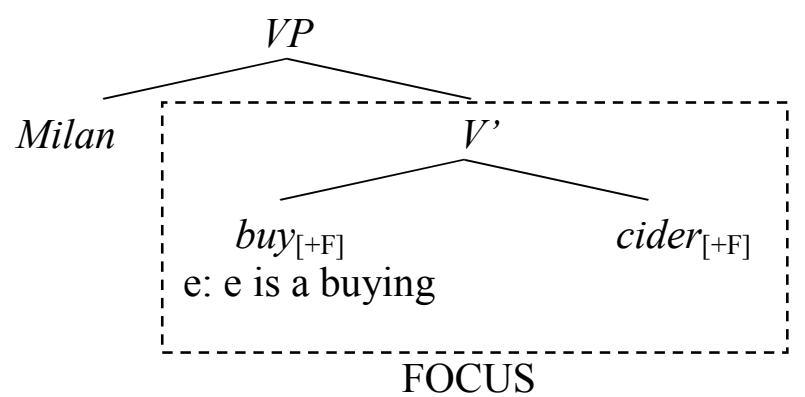

But now, a puzzle arises: the just sketched proposal proclaims a binary quantifier taking a restriction and a scope as the logical form representation of a sentence, but this configuration does not come for free. If we want to keep with the most commonly assumed (but not so commonly mantained) proposal that the syntax-semantics mapping is transparent and a direct function of the syntactic structure and the lexical meanings of the words it contains, the intended representation will have to be derived as a direct mapping from an LF syntactic structure that mirrors the postulated semantics. Thus, in order to get the desired results at logical form, Herburger proposes a process of "focal mapping" operation by which the nonfocused material in the c-command of the existential quantifier rises to its restriction (Herburger (2000: 43)):

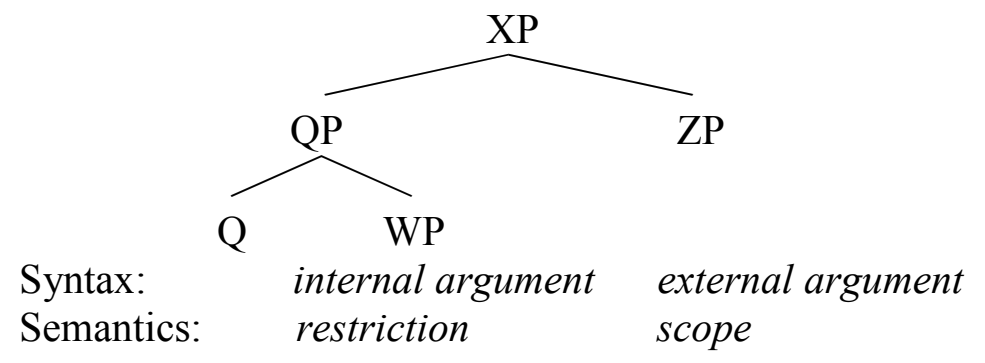

\footnotetext{
${ }^{7}$ I will leave the issue of where the existential quantifier comes from for Section 4.2.
} 
Next, in Section 4, I will present the Basque focus data and propose a derivational analysis of them based in the logical form representation for focus just presented and adopting the reprojection analysis of binary quantifiers of Hornstein \& Uriagereka (2002). As will be argued in 4.2, the proposal will give us a focus LF representation akin to that of (20) through a transparent syntax-semantics mapping.

\section{4-Focus in Basque}

\subsection{The Data \& Discussion of previous literature}

As already shown in Section 2, it is a well-known fact that (Central-Western) Basque shows Focus-Verb adjacency (see among others Ortiz de Urbina (1983, 1986, 1999), A. Elordieta (2001), Arregi (2003a), or, more generally, Hualde \& Ortiz de Urbina (2003)). Thus, the sentence in (21a) is ungrammatical because the focalized subject and the verb are not adjacent whereas the variants in $(21 b-c)$ are grammatical: ${ }^{8}$
a. $\quad *[\mathrm{JONEK}]_{\mathrm{F}}$ mahaia hautsi du.
Jon table broke AUX
' $[\mathrm{John}]_{\mathrm{F}}$ broke the table'
b. Mahaia $[\mathrm{JONEK}]_{\mathrm{F}}$ hautsi du.
c. $\quad[\mathrm{JONEK}]_{\mathrm{F}}$ hautsi du mahaia.

The traditional way of analyzing these data has been in terms of the 'Left Peripheric' approach, that is, by the postulation of a strong $[+\mathrm{F}]$ feature that has to be checked against the verb in a Spec-Head configuration in a functional projection (traditionally CP or FP):

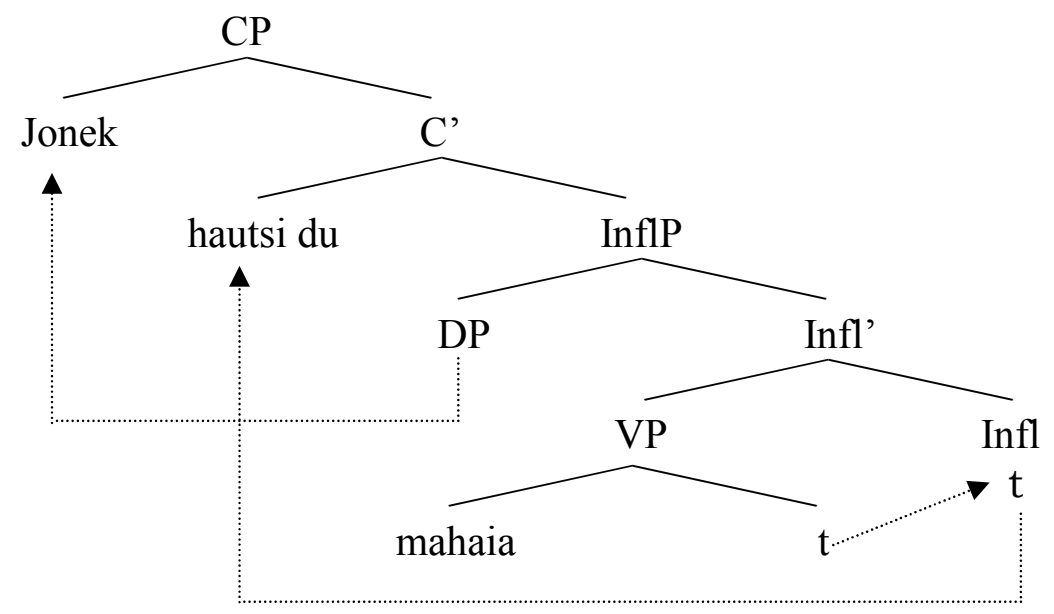

\footnotetext{
${ }^{8}$ There are also some highly contrastive constructions like those analyzed in Ortiz de Urbina (2003). These are cases where the focus appears at the right edge of the clause preceded by the rest of the sentence. For instance, the example (i) could be a variant of (21):

(i) Mahaia hautsi du [Jonek $]_{\mathrm{F}}$. I won't discuss these types of constructions here ( $c f$. Irurtzun (2005b, 2005c).
} 
On the other hand, and contrary to the Left Peripheric approach, under the NSR based theory of focus, the movements that derive the surface word order are not instances of feature checking, but movements in order to fulfill the legibility condition on derivations that requires focused elements to bear the $N S$ at PF. Thus, according to the Cinquean version of the NSR, when a non-focused element is in the most embedded position in the clause, a 'nuclear stress avoiding' movement of this nonfocused element takes place so that the focused element becomes the most embedded element in the structure and thus it gets the $N S$. These types of movements are the 'scrambling' mechanisms of A. Elordieta (2001) or the left and right dislocations of Arregi (2003a). A representation of the structure of the sentence (21c) under Arregi's proposal is below:

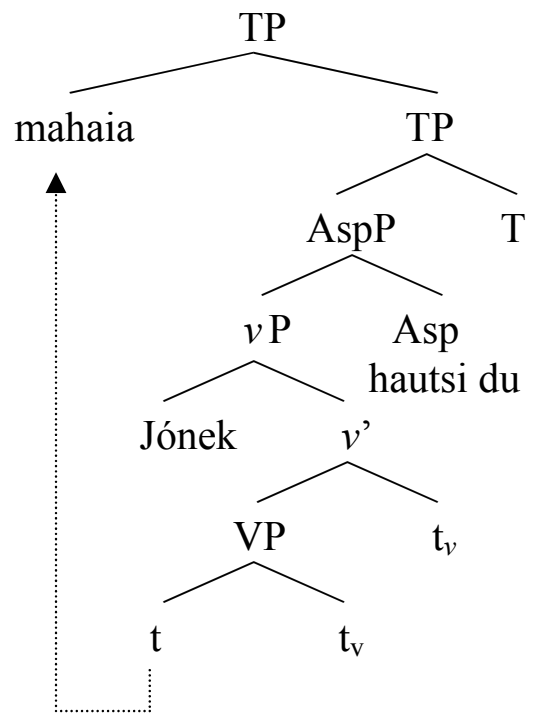

According to this proposal, the surface Focus-Verb adjacency is just accidental, a byproduct of the 'stress avoiding movements' of the non-focused elements and the configuration of the lowest part of the clause.

Having this in mind, let's review some data that show how the left peripheric approach is superior to the NSR-based one when attempting to account for the displacements triggered by focus:

\subsection{1-Long-Distance focus movements:}

In cases where the $[+\mathrm{F}]$ feature is in an embedded $\mathrm{CP}$, long distance (LD) movement can take place up to the matrix $\mathrm{CP}$, just the same as with the [+Wh] feature (cf. Eguzkitza (1986), Ortiz de Urbina (1989) or Hualde \& Ortiz de Urbina (2003) among others). Arregi (2003a) discusses data like those in (23):

$$
\begin{aligned}
& {[\mathrm{JON}]_{\mathrm{F}} \text { pentsatzen dut [CP Mirenek } t \text { ikusi zuela] }} \\
& \text { Jon think AUX Miren seen AUX } \\
& \text { 'I think Miren saw [Jon }]_{\mathrm{F}}
\end{aligned}
$$

According to his analysis, the focus is extracted from its base-generated position, adjoining it to the matrix $v \mathrm{P}$, and then, the embedded $\mathrm{CP}$ is right-dislocated. 
Setting asside the shaky foundations of these untriggered movements, I don't share the judgments in Arregi (2003a), judging this sentence as deviant. ${ }^{9}$ This, of course, is meaningless for the analysis in Arregi (2003a), which might be correct to account for the data in (23). But this analysis cannot account for the type of Long Distance Movement constructions that I and my informants find to be the optimal ones. These are sentences like (24a). A non-LD movement variant of (24a) can be found in $(24 b):^{10}$

$$
\begin{aligned}
& \text { a. }[\mathrm{JON}]_{\mathrm{F}} \text { pentsatzen dut }[\mathrm{CP} \text { ikusi zuela Mirenek }] \\
& \text { think AUX seen AUX Miren } \\
& \text { 'I think Miren saw }[\mathrm{Jon}]_{\mathrm{F}} \text { ' } \\
& \text { b. Pentsatzen dut }\left[\mathrm{CP}[\mathrm{JON}]_{\mathrm{F}}\right. \text { ikusi zuela Mirenek] } \\
& \text { think AUX Jon seen AUX Miren } \\
& \text { 'I think Miren saw [Jon }]_{\mathrm{F}}
\end{aligned}
$$

Unless some untriggered movements are postulated, in neither case is 'Jon' in the most embedded position, and therefore, neither of the subjects in (24a) or (24b) can be focused according to the analysis in Arregi (2003a). Furthermore, it seems that the focus-verb adjacency is not a byproduct of these purported movements since this configuration is not restricted to the clause that contains the focus, rather, it is observed in all the clauses where the focus moved through. Given that the focus always appears at the left edge of the clause (be it the matrix one as in (24a), or in the embedded one as in (24b)) I think that it is more appropriate to assume some variant of the classical left peripheric analysis, at the risk of having to stipulate some special relationship between the focus and the verb (see below). In fact, with respect to the left peripheric behavior of the focus, quite the same picture arises with the clausal pied-piping phenomena.

\subsection{2-Pied-piping phenomena:}

From a minimalist point of view, one of the most striking phenomena of natural languages is that of clausal pied-piping in languages like Basque. In this language, as far as the classical analysis goes ( $c f$. Ortiz de Urbina $(1989,1993))$, clausal pied-piping can take place when an element bearing a $[+\mathrm{Wh}]$ or $[+\mathrm{F}]$ feature in a subordinate clause moves through Spec/CP position of this clause. On the other hand, according to Arregi (2003a)'s analysis, the same movements as those proposed for the LD movement sentences take place, with the difference that in pied-piping constructions it is not only the focused XP extracted from the embedded clause that adjoins to the matrix $v \mathrm{P}$, but the entire subordinate clause:

\footnotetext{
${ }^{9}$ In both Ortiz de Urbina (1983) and Laka \& Uriagereka (1987), constructions like (23) appear with a *. I (and my informants) don't feel that the deviance is that strong, maybe, enough to be marked as a ? (or ??, as in Ortiz de Urbina (1986)). At any rate, as will be argued (see below), the important fact here is that for some speakers, the optimal realization of a LD-moved focus is that in (24a), not that in (23), and unless one more ad hoc movement is posited to derive the Subject-Verb inversion of the embedded clause, (24a) cannot be derived under Arregi's analysis.

${ }^{10}$ Given the interpretive and intonational properties of $(24 b)$, it seems to me that the matrix phrase 'pentsatzen dut' is somehow topicalized and that this sentence is an instance of a 'right periphery' focus (cf. Ortiz de Urbina (2003), Irurtzun (2005a)).
} 
Again the same puzzle arises. His proposal fits his data; my judgements (and those in Laka \& Uriagereka (1987) and Ortiz de Urbina (1983, 1999)) judge these sentences as ungrammatical or deviant. ${ }^{11}$ Our judgements for a grammatical sentence with pied-piping are along the lines of $(26):^{12}$

$$
\begin{aligned}
& {\left[[\mathrm{JON}]_{\mathrm{F}} \text { etorriko dela bihar }\right] \text { esan diot Mireni. }} \\
& \text { Jon come AUX-C tomorrow said AUX Miren-to } \\
& \text { 'I told Mary that }[\mathrm{Jon}]_{\mathrm{F}} \text { will come tomorrow' }
\end{aligned}
$$

Again, unless more movements are posited, the focused element is not in the most embedded position in the clause, so the sentence should be ungrammatical according to Arregi's analysis. But at least for some speakers it is not.

As in the previous example, the focus appears at the left edge of the clause (suggesting the appropriateness of a left peripheric analysis) and V2-like phenomena are observed in all the clauses, something I will analyze in the next Section. ${ }^{13}$

\subsection{3-Dialectal Variation}

As has already been shown, in languages like (Central-Western) Basque, focus has to show/shows surface adjacency to the verb (27b-c) and sentences without this adjacency are ungrammatical (27a):
a. $\quad *[\mathrm{JONEK}]_{\mathrm{F}}$ mahaia hautsi du. Jon table broke AUX ' $[\mathrm{Jon}]_{\mathrm{F}}$ broke the table'
b. Mahaia $[\mathrm{JONEK}]_{\mathrm{F}}$ hautsi du.
c. $\quad[\mathrm{JONEK}]_{\mathrm{F}}$ hautsi du mahaia.

As explained before, the Cinquean analysis for these data proposes that 'nuclear stress avoiding' movements take place in order for the non-focused material not to get the nuclear stress. Recently, two versions of this type of analysis have been proposed for Basque:

\footnotetext{
${ }^{11}$ Obviously, the variability in the judgments could be derivative of a dialectal or idiolectal variation among speakers. But, if we seek for a unitary analysis of the data, a proposal under Arregi (2003a)'s terms doesn't seem to be appropriate to account for the cases that show verb-movement in (24), (26) or some of the data reported in Arregi (2003b).

12 Actually, not even (26), since it is a bit marked with the adverb in final position in the pied-piped clause. Iit would improve with the adverb fronted as in (i) but I will disregard this interesting issue now for the sake of the argument:

(i) $\left[\right.$ Bihar $[\mathrm{JON}]_{\mathrm{F}}$ etorriko dela $]$ esan diot Mireni. Tomorrow Jon come AUX-C ${ }^{\text {o }}$ said AUX Miren-to 'I told Mary that [Jon] $]_{\mathrm{F}}$ will come tomorrow'

13 This doesn't mean that these are instances of V2 as in German. It seems that these are very different phenomena ( $c f$. Ortiz de Urbina (1995) and Uriagereka (1999)).
} 
-A. Elordieta (2001): Scrambling to prevent a non-focused element to receive Nuclear Stress. ${ }^{14}$

-Arregi (2003a): Left and right dislocations to avoid a non-focused element to receive Nuclear Stress.

Thus, as I have already said, for these approaches, Focus-Verb adjacency is just accidental, a by-product of NSR driven displacements and the configuration of the lowest part of the clause ( $c f$. ex. 22). In other words, there is no special syntactic or phonological reason for the Focus-Verb adjacency; things just happen to be like this.

However, a look at Eastern dialects of Basque shows us that this adjacency is not accidental, since what we find in these dialects is not Focus-Verb adjacency but FocusAuxiliary adjacency ( $c f$. Ortiz de Urbina (1989, 1995), Laka (1990), and, more generally, Hualde \& Ortiz de Urbina (2003)):

(28) Eastern Basque (M. Duguine, D. Duguine, J. Pochelu ( p.c.)):

a. Mahaia $[\mathrm{JONEK}]_{\mathrm{F}}$ du hautsi. table Jon AUX broke '[Jon $]_{\mathrm{F}}$ broke the table'

b. $\quad[\mathrm{JONEK}]_{\mathrm{F}} \mathrm{du}$ mahaia hautsi. Jon AUX table broke '[Jon $]_{\mathrm{F}}$ broke the table'

Note that, given the clause structure of (22), no accidental adjacency could arise between the focused element and the auxiliary in (28a-b) just by the "left dislocation" or "scrambling" of the non-focused XP. Here, it really seems to be focus-auxiliary adjacency that matters in Basque focalizations. In that case, the surface focus-verb adjacency observed in Central Basque could be derived via a further movement (piedpiping of the verbal complex or head movement of the verb).

\subsection{4-Focus in Infinitive Constructions}

This point is a corollary to the previous one: if it is the inflected auxiliary what really is left adjacent to the focused XP, the prediction is that whenever we don't have an auxiliary, the verb won't necessarily be left adjacent to the focus. This is precisely the pattern that we find in Basque: when we construct examples with infinitival subordinate clauses, the verb in the infinitival clause doesn't undergo movement, whereas the inflected verb in the matrix one does. Compare in the following dialogue the out-of-the-blue uttered by A with the correction of B:

(29) A: [Kepak ardoa edate-a] gauza arraroa da.

Kepa wine drink-INF thing strange BE

"It is a strange thing for Kepa to drink wine"

\footnotetext{
${ }^{14}$ Actually, the analysis of A. Elordieta is a combination of the left peripheric and the NSR-based approaches ( $c f$. Elordieta (2001) for further details).
} 


\section{B: $\quad$ Ez!, [[Julenek $]_{\mathrm{F}}$ ardoa edate-a] da gauza arraroa! ${ }^{15}$ No Julen wine drink-INF BE thing strange \\ "No!, It is a strange thing for [Julen] $]_{\mathrm{F}}$ to drink wine!"}

These examples show that the reason for the adjacency lies in the auxiliary, since in its absence, the verb in the subordinate clause doesn't move, and the sentence still is grammatical. Furthermore, they point towards the appropriateness of a PF analysis of this adjacency, precisely because if the reason for the adjacency was syntactic (some sort of feature on the focus that has to be checked against the tense), sentences like (29B) or the rightward focus constructions ( $c f$. footnote 10) would be ungrammatical $^{16}$. Likewise, the movement of the verbal complex observed in long distance focus movements could be analyzed along the same lines: the affixation could apply before the copies of the moving phrase are deleted. Thus, the lack of total ungrammaticality of the long distance movement and pied-piping constructions where the movement of the verb does not apply could be analyzed as a phonological violation, not as incurring in a derivational crash.

\subsection{5-Summing up}

To sum up this subsection on Basque data, focalizations in Basque seem to be instances of syntactic movements to some left peripheric head and not accent-triggered movements to satisfy a purported PF requirement; hence, they show many of the properties and restrictions of other syntactic movement like Wh-movement. Furthermore, the focus-verb adjacency should be analyzed as masking a true focus-tense relation; a relation that, as I will argue shortly, can be better analyzed as a PF phenomenon where tense is an affix of the focus.

\subsection{The Analysis}

We saw that the semantic analysis of focus adopted in Section 3 assumes an logical form representation by which the existential quantification over events takes the non-focused part of the clause as the restriction and the whole clause (with the focused chunk inside) as the scope. Thus, I want to propose a new analysis of focalization based in a Spell Out satisfaction of some interface conditions: namely, a PF bare output condition on linearization and an LF ban on vacuous quantification. As argued in Section 3, at the end of the derivation, the desired result is one in which, for instance, in a sentence with focus on the object we get focus-verb adjacency at PF for Central Basque (or focus-AUX adjacency for Eastern Basque ((30a-b) respectively)). At logical form, we get a restricted quantification over events where all the material but the $[+\mathrm{F}]$ marked element is in the restriction, and all the material (including that with the $[+\mathrm{F}]$ feature) is in the scope of this quantification. This is represented in the logical form of (30c):

\footnotetext{
${ }^{15}$ This is not the only possibility, since some speakers accept also the variant of (29B) with focus-verb adjacency ( $c f$. also Ortiz de Urbina (1983)). As I will propose in the next Section, if we take this focusverb adjacency to be the result of a pure PF phenomenon (viewing tense as a focal affix) the adjacency of the focus to the uninflected verb could be analyzed as a hypergeneralization, since even the speakers that accept such a configuration have a clear preference for the one in (29B). A more 'syntactic' trigger for this adjacency would be highly problematic.

${ }^{16}$ The lack of affixation of the auxiliary to the focus in rightward foci could be derivative of them being somehow 'too far' from each other, arguably, having been spelled out in different steps ( $c f$. Irurtzun $(2005 b))$.
} 
a. $\quad[\text { Ogia }]_{F}$ jan du Urtzik. bread eat AUX Urtzi

'Urtzi ate $[\text { bread }]_{\mathrm{F}}$ '

b. $\quad[\text { Ogia }]_{\mathrm{F}}$ du Urtzik jan. bread AUX Urtzi eat

'Urtzi ate $[\mathrm{bread}]_{\mathrm{F}}$ '

c. $\quad \exists$ e [Eat(e) \& Past(e) \& Agent(e, Urtzi)] [Theme(e, bread) \& Eat(e) \& Past(e) \& Agent(e, Urtzi)]

In order to explain my analysis of these constructions, I will first introduce one of the bases of my proposal: the mechanism of 'reprojection' proposed by Hornstein \& Uriagereka $(1999,2002)$.

\subsection{1-Reprojections:}

Hornstein \& Uriagereka $(1999,2002)$ start out from the relational view of binary quantifiers proposed in Larson (1991) and Larson \& Segal (1995). According to this proposal, quantifiers are basically predicates of sets and binary quantifiers are dyadic predicates in that they take their "arguments" (the Q's restriction and scope) in an ordered way. For instance, when interpreting the sentence of (31), we create a subset/superset relation between two sets; the set of 'whalehood' and the set of 'mammalhood' (32):

(31) All whales are mammals.

(32) $\quad\{\mathrm{y}: \mathrm{y}$ is a whale $\} \subseteq\{\mathrm{x}: \mathrm{x}$ is a mammal $\}$

As argued by these authors, a natural way of capturing this asymmetry is to take the quantifier 'all' to be a predicate that takes the sets of 'whalehood' and 'mammalhood' as its internal and external arguments respectively:

$$
\operatorname{ALL}(\{\mathrm{y}: \mathrm{y} \text { is a whale }\})(\{\mathrm{x}: \mathrm{x} \text { is a mammal }\})
$$

Thus, the truth conditional difference between a sentence like (31) and a sentence like (34) would derive from the ordering of the arguments: ${ }^{17}$

(34) All mammals are whales.

In order to guarantee the locality of the Q's argument-taking, and since the external argument of the Q is not evidently in its local domain (in the case of (31), the phrase ' $t$ are mammals' is not in the projection of the Q 'all'), Larson (1991) proposes

\footnotetext{
${ }^{17}$ Recall that a unary quantifier like 'some' wouldn't induce any truth conditional difference between analogous examples as in (i) and (ii):

(i) Some whales are mammals.

(ii) Some mammals are whales.

Thus, unary quantifiers have to be treated as monadic predicates (cf. Hornstein \& Uriagereka (2002: 124125).
} 
that a silent pro is merged in the specifier of $Q$ as in (35), thus providing the locus of the scope of the Q. He further proposes that this pro will get coindexed with the scopal phrase that gives it a value at LF, after QR (36):

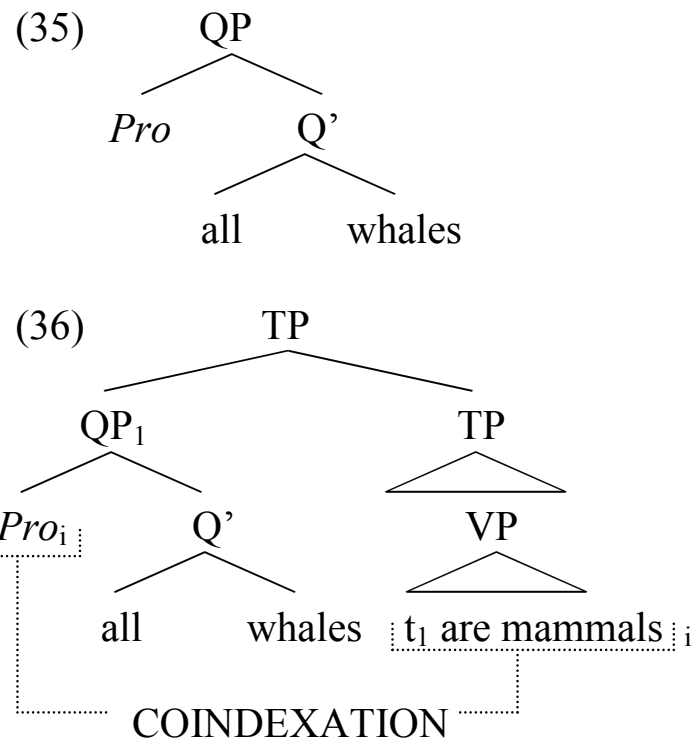

Thus, the projection requirements of the predicative Q are satisfied, since it takes its restriction ('whales') by first merge, and its nuclear scope when the phrase 'all whales' is merged with the pro in its specifier. As can be observed, this is a very natural way of capturing the conservativity of natural language quantifiers (or, in Barwise \& Cooper (1981)'s terms, what the Q lives on).

Going a step further and implementing the relational view of quantifiers just sketched, Hornstein \& Uriagereka $(1999,2002)$ propose in pure 'Bare Phrase Structure' terms that a given phrase marker could have different labelings at different stages of the derivation. This would arise via a reprojection mechanism. A reprojection turns a phrase marker $\{\mathrm{Y},\{\mathrm{Y}, \mathrm{X}\}\}$ into a phrase marker $\left\{\mathrm{X},\{\mathrm{Y}, \mathrm{X}\}:^{18}\right.$

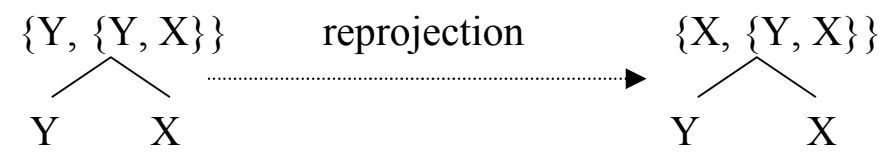

According to these authors' analysis, and applying the idea that quantifiers are predicates, by way of reprojection, we can ensure the locality of quantifiers' argumenttaking without the stipulation of a null pro in their specifier. With their proposal, binary quantifiers like 'most' in (38a), having acquired their 'internal argument' (i.e., the restrictor 'people') by just being merged with them, can get the 'external' argument (i.e., the scope) in the course of derivation. Following Hornstein \& Uriagereka's proposal, we can ensure the locality of the semantic composition of the $\mathrm{Q}$ and its arguments if we allow the Q to reproject higher up in the phrase, turning the phrase marker that at some derivational time $D t$ was $\{\mathrm{I},\{\mathrm{Q}, \mathrm{I}\}\}$ into $\{\mathrm{Q},\{\mathrm{Q}, \mathrm{I}\}\}$ at a later derivational time $D t$ '. This reprojection, by extending the Q's projection space, allows the $\mathrm{Q}$ to take the external argument ' $t$ love children' in its extended local domain:

\footnotetext{
${ }^{18}$ Formally, this mechanism will be just a label 'projection' that takes place for the second time in the same geometrical object.
} 
(38) Most people love children.

Derivational Time $D t$ :

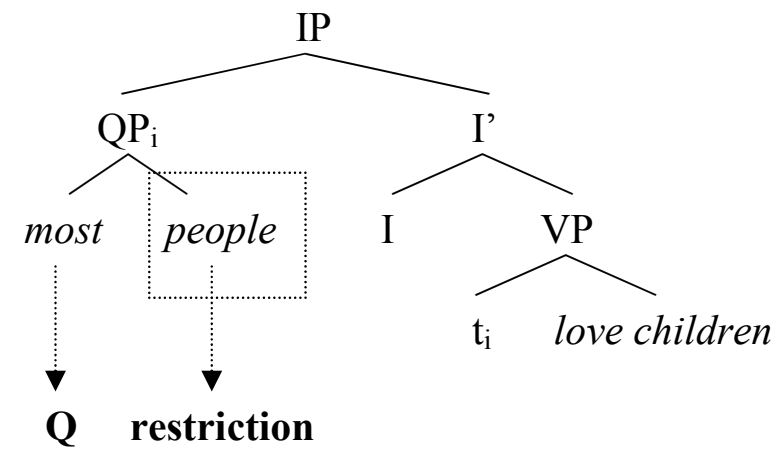

Derivational Time $D t^{\prime}$ (after reprojection of the Q):

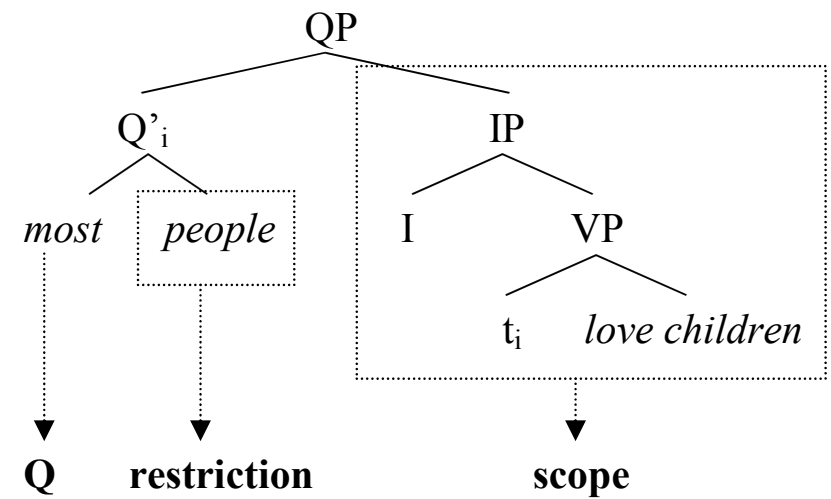

Besides of providing a neat syntax-LF mapping, the analysis has some welcome empirical consequences like predicting quantifier-induced islands or accounting for some definiteness effects that appear in nonexistential contexts (see the next section and Hornstein \& Uriagereka (2002) for further details). Given that, I will adopt this proposal as a necessary condition in order to get the desired quantificational structure in logical form (see Herburger (2000) and the Section 3 of this work). So let's see how such an LF could be obtained in a derivational fashion.

\subsection{2-Derivation of LF:}

Assuming a direct mapping from syntax to LF and minimalist desiderata, the first question that we have to solve is the following: Where does the (implicit) Davidsonian existential quantifier come from if we are not going to violate the Inclusiveness Condition?

Let's look again at the sentence in (19a) (represented here as (39a-b) for convenience): 


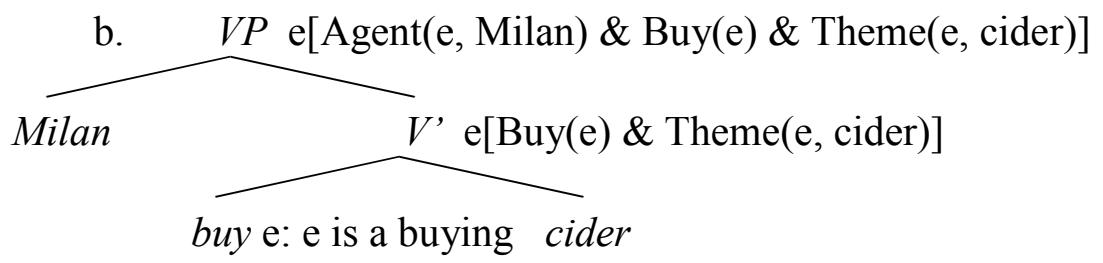

Since the $v \mathrm{P}$ denotes a property of events and not yet a truth value, scholars like Higginbotham (1985) or Kratzer (1996) have proposed that some higher functional head introduces the existential closure to the event denoted by the verb; according to their proposals it is $\mathrm{Infl}^{\circ}$. The idea is appealing but we would run into a problem whenever we had $\mathrm{T}^{\mathrm{o}}$ (or $\mathrm{Infl}^{\circ}$ ) marked as $[+\mathrm{F}]$ as well as in an infinitival construction like those shown in 29. ${ }^{19}$ Furthermore, there is convincing evidence against treating Tense as an operator and arguing that it should rather be regarded as a predicate of events that orders the event time with respect to the utterance time (cf. Stowell (1996), Demirdache \& Uribe-Etxebarria (2000) and Higginbotham (2002) among others). Given this state of affairs, another syntactic node will have to introduce the existential quantification for the event denoted by the verb. Looking at the literature, one of the options seems to be to assume some version of the 'split CP' proposed by Rizzi (1997) and presented in Section 2:

$$
\text { Force .... (Topic) ... (Focus) ... Fin ... IP }
$$

Adopting this system, I would like to propose that it is the Finiteness head that introduces the binary existential quantifier to the event denoted by the verb, whereas Tense (or Infl) introduces a temporal predicate of events that combines with the $v \mathrm{P}$ via predicate conjunction:

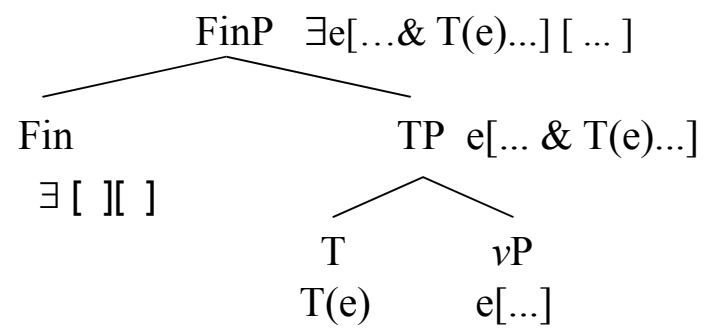

Now, assuming the Derivational Approach to the Focus Structure presented in Section 4 and the phrase structure in (41), I would want to propose a derivational approach to the structure of sentences like (30a-b) (repeated here as (42a-b) respectively):

\footnotetext{
${ }^{19}$ Examples of focused tenses might not be very common but I think this is a matter of information flow ('informatics' in the sense of Vallduví (1993)) and not of a restriction in the computational system. Sentences where the 'new information' is given by the tense are quite uncommon and need a very contrastive environment to be plausible; however, relevant examples can be constructed in contrastive environments like (i):

(i) A: I heard that John is married.

B: No, he WAS married!

Thus, we have to allow for the possibility of focalized tenses.
} 
a. $\quad[\text { Ogia }]_{F}$ jan du Urtzik.

bread eat AUX Urtzi

'Urtzi ate $[\text { bread }]_{\mathrm{F}}$ '

b. $\quad[\text { Ogia }]_{F} d u$ Urtzik jan.

bread AUX Urtzi eat

'Urtzi ate $[\text { bread }]_{\mathrm{F}}$ '

For instance, for the sentence (42a) we arrive to a derivational stage like (43) where the Fin $^{\circ}$ (i.e. the lexically binary $\exists$ ) has been merged with TP (cf. (41)):

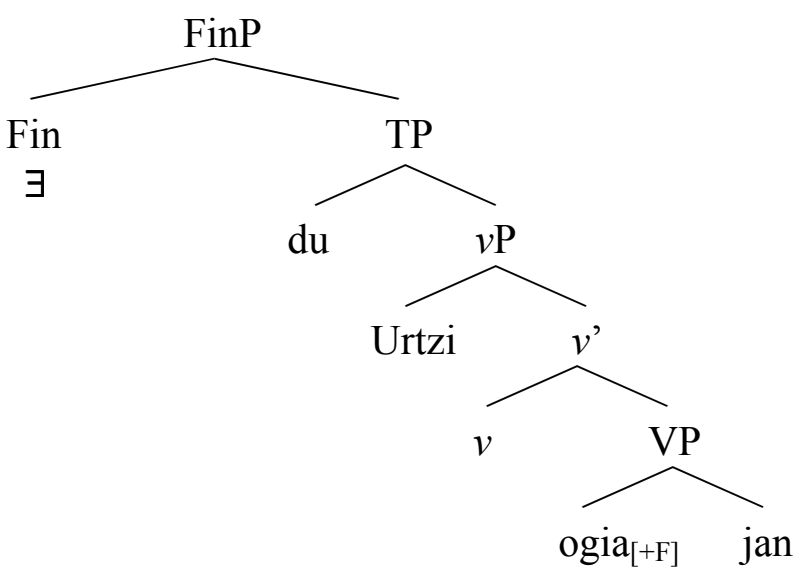

Then, following Ortiz de Urbina (1999) or Rizzi's (1997) system again, the Focal head Foc $^{\circ}$ is merged, attracting the Focus to its specifier: ${ }^{20,21,22}$

\footnotetext{
${ }^{20}$ The object probably isn't in situ but in the outer specifier of $\nu \mathrm{P}$ for case checking, but let me abstract away from case issues here.

${ }^{21}$ Given the "derivational approach to focus structure" presented in Section 3.1. I will assume that the focal head attracts all the $[+\mathrm{F}]$ featured material (cf. Bošković (1999) and Jeong (2003)). Furthermore, this operation of attraction of all the $[+F]$ featured material could be the trigger of the $\mathrm{A}^{\prime}$ movement involved in fragment answers as those analyzed in Merchant (2004).

${ }^{22}$ As will be shown in short, in order to get the desired semantics (and PF), this movement will have to leave no copy behind (or the copy will have to be necessarily deleted). This argument, stipulative as it is, seems to be necessary given that focus movements in Basque show scope-freezing effects where reconstruction is impossible. For instance, the sentence in (i) with a focalized object lacks the reading where the universal quantifier takes scope over the existential one:

(i) $\quad[\text { Txakur bat }]_{\mathrm{F}}$ maite dute haur guztiek. $\quad \sqrt{ } \exists>\forall, * \forall>\exists$

dog one love AUX child all

'All the children love one dog'
} 
(44)

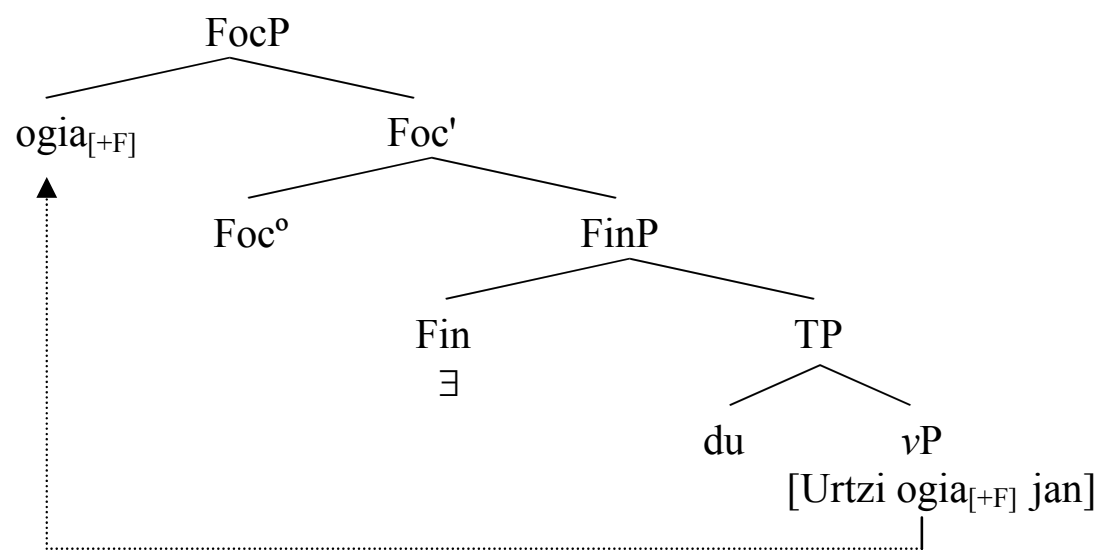

The Top ${ }^{\circ}$ head is merged next:

(45)

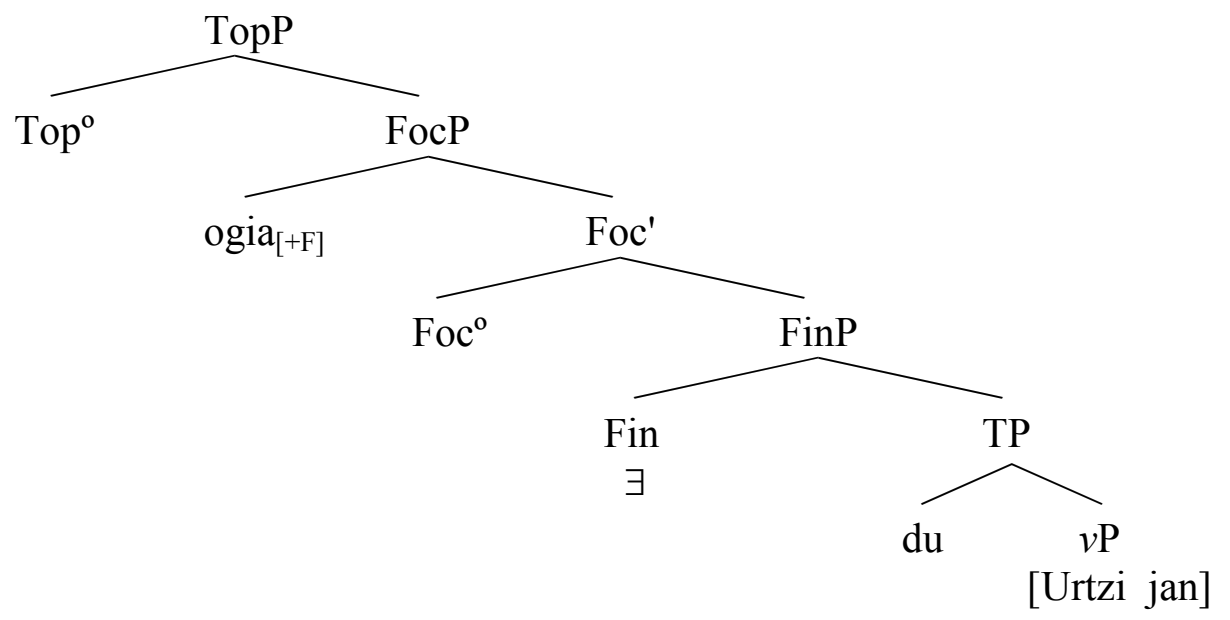

Now, following the relational view of quantifiers of Larson (1991) and Larson \& Segal (1995) and the reprojection mechanism proposed in Hornstein \& Uriagereka $(1999,2002)$, I want to suggest that the lexically binary existential quantifier in Fin ${ }^{\circ}$ that got its "internal argument" (TP) when first merged, but that at this derivational stage lacks the "external argument" (i.e., the scope), will undergo an operation of Quantifier Rising to the next available position (the specifier of $\mathrm{Top}^{\circ}$ ), (46). Then, it reprojects, thus gaining the "external argument" in its extended local domain (47): $:^{23}$

\footnotetext{
${ }^{23}$ Note that this QR movement, if overt (see below), could be the trigger for the remnant movement operations argued for in Uribe-Etxebarria (2002) and Ortiz de Urbina (2003) when analizing "in situ"like Wh constructions and corrective focalizations in Spanish and Basque respectively. Thus, as I argued in Irurtzun (2005a), we could derive both unmarked (XP fronted) and marked (XP "in situ") constructions in a unitary way (pace Dominguez (2004)). The asymmetries between both constructions would derive simply from timing differences between the reprojection and Spell Out.
} 
(46)

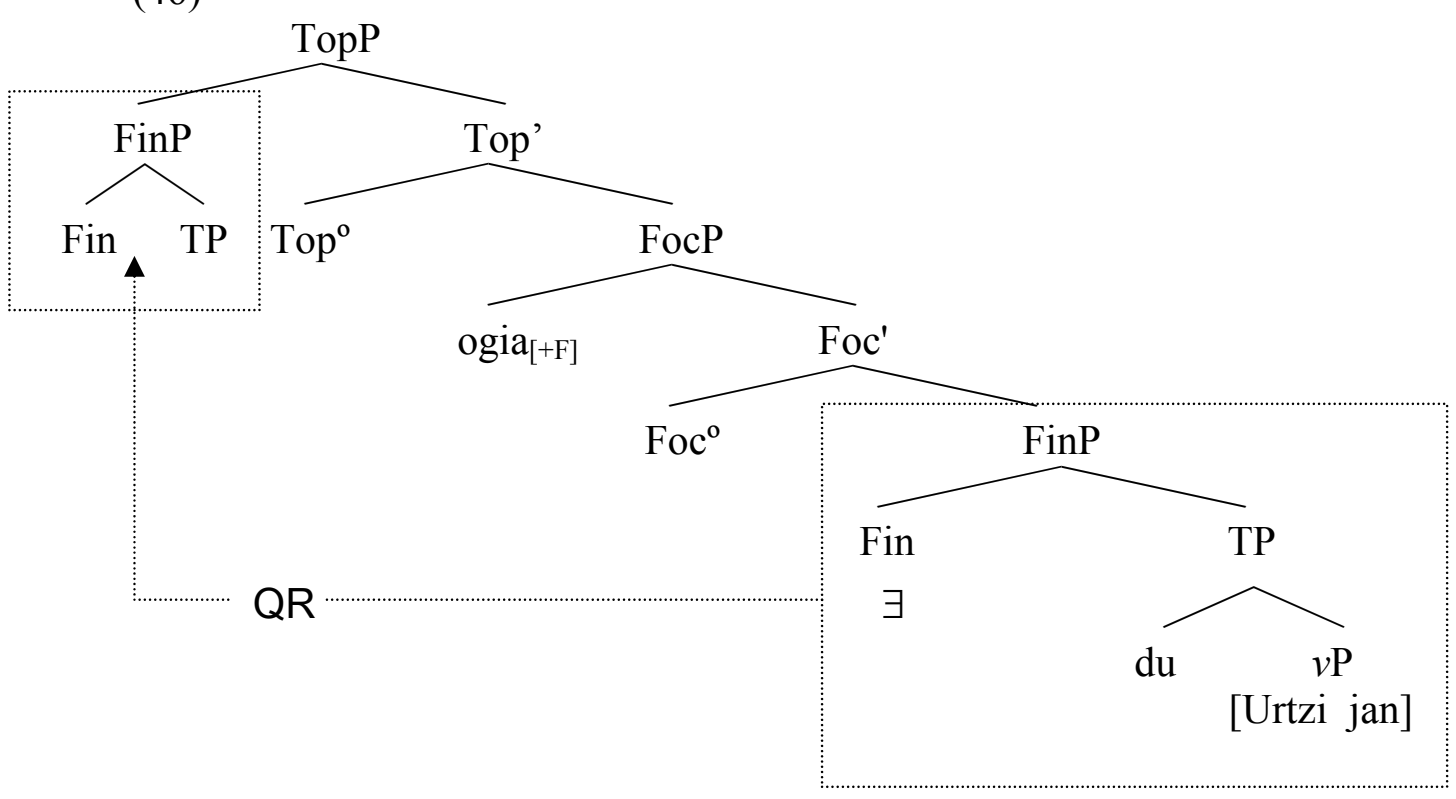

(47)

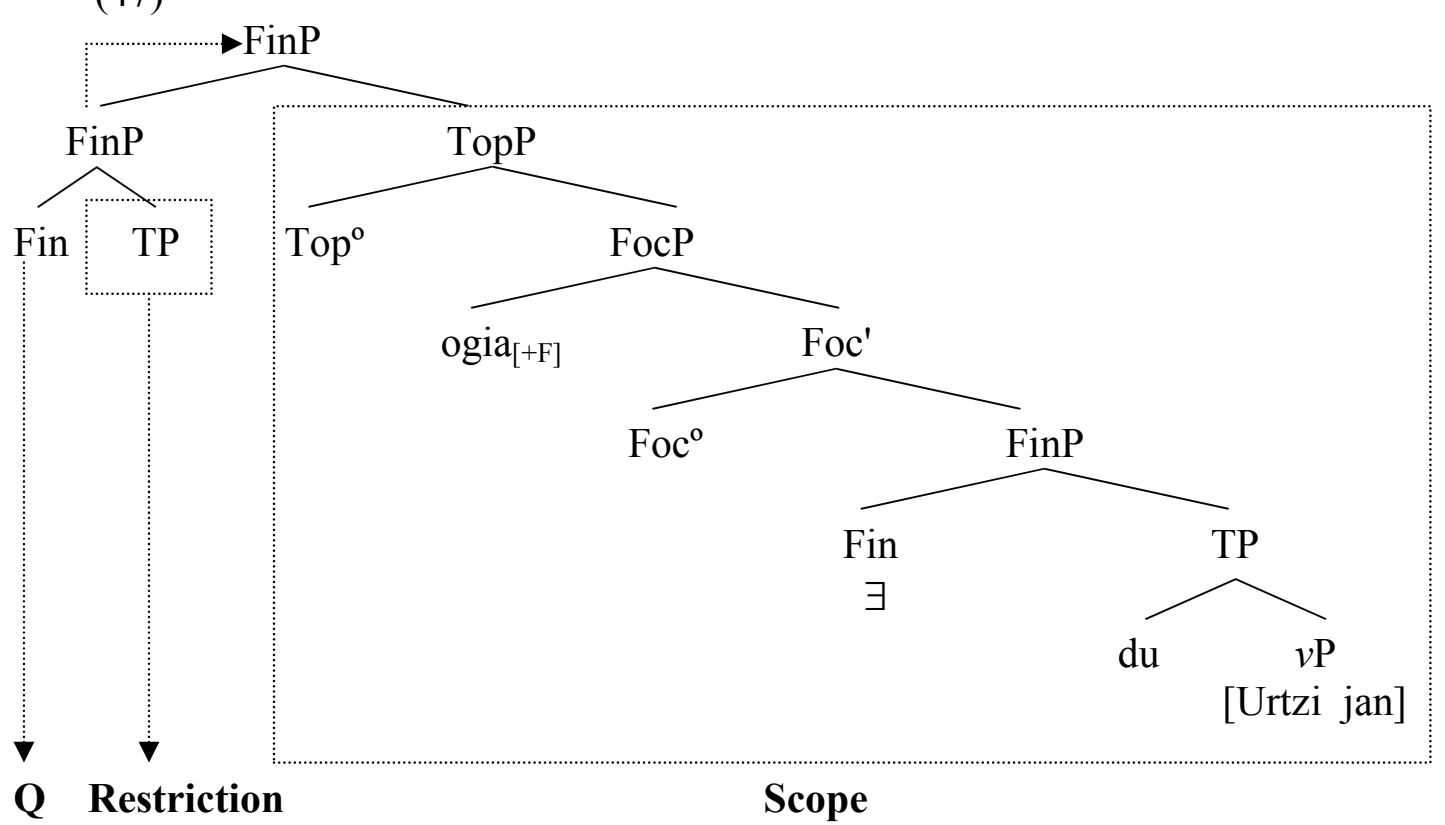

That is, by way of the reprojection, we get the quantificational phrase $(\mathrm{Fin} \mathrm{P} / \exists \mathrm{P})$ at the top node dominating a quantifier $(\exists)$, its restriction (TP) and its scope (TopP). ${ }^{24}$

Here, a possible puzzle arises concerning the timing of the reprojection: that a reprojection could take place overtly is seen as problematic by Hornstein \& Uriagereka, who argue that it would change the checking relations (notably for case and agreement). Hence, they claim that reprojections would have to take place covertly and very late in the derivation, once all these relations have already been exploited in overt syntax. However, in principle, there should be no problem in having a system where reprojection can take place after all agreement relations are set, and just before Spell Out (as potentially in the proposal just sketched for focus, where the reprojection of Fin ${ }^{\circ}$

\footnotetext{
${ }^{24}$ Obviously, after QR, some 'trace conversion' will have to take place deleting the lower existential quantifier.
} 
takes place in the 'C-domain'). ${ }^{25}$ On the other hand, and as one of the welcome empirical predictions that Hornstein \& Uriagereka's proposal brings, it is a late application of the reprojection that allows them to account for the quantifier-induced island phenomena (cf. Hornstein \& Uriagereka $(1999,2002))$. I won't enter here in the discussion of the timing of the reprojection and spell out (cf. Irurtzun $(2005 \mathrm{~b}, 2005 \mathrm{c})$ ), and I will simply assume that both $\mathrm{QR}$ and reprojection take place covertly. Thus, after spell out, we get a PF representation of (42) where the focal object is linearized first, followed by the tense, subject and verb:

$$
\mathrm{O}_{[+\mathrm{F}]} \mathrm{T} \mathrm{S} v \mathrm{~V}
$$

Given that, I would like to suggest a PF affixation analysis of the problematic nature of the Focus-Verb adjacency: Adapting the recent proposals of Chomsky (2000, 2001) or Boeckx \& Stjepanović (2001) that head movement takes place at PF, I would like to postulate that PF head-lowering applies in Central Basque, leaving the verbal complex $[\mathrm{V}+v+\mathrm{T}]$ at the right edge of the string. Then, the affixation of the tense and, with it, the movement of the whole verbal complex to the focal phrase, will give us the word order that we observe in Central Basque, whereby the focus is left-adjacent to the verb in PF:

$$
\text { (49a) } \mathrm{O}_{[+\mathrm{F}]}[\mathrm{V}+v+\mathrm{T}] \mathrm{S}
$$

$$
\begin{gathered}
\text { (49b) }[\text { Gazta }]_{F} \text { jan du Urtzik } \\
\text { cheese eat AUX Urtzi } \\
\text { 'Urtzi ate [cheese }]_{F} \text { ' }
\end{gathered}
$$

Thus, the asymmetry observed between Eastern Basque and Central Basque would be derived from the availability (in the Central dialects) or unavailability (in the Eastern ones) of the T-lowering ((42a) and (42b) respectively). ${ }^{26}$

Furthermore, this analysis of tense as being affixed to the focus phrase might help us understanding the word order observed in out-of-the-blue sentences (S-O-VAUX). These sentences could be analyzed as being structurally simpler (involving less projections and transformations) than sentences where an argument or adjunct is in focus: whereas in adjunct or argument focalizations displacements are involved, in outof-the-blue (all new) sentences, all the elements would remain in situ. A reason for that could be that the complementizer system of both constructions is different (involving different Fin $^{\circ}$ heads): in argument or adjunct focalizations a binary quantifier is merged and in out-of-the-blue sentences the quantifier is unary (lacking any restriction). Likewise, in out-of-the-blue sentences there won't be any need for a Foc ${ }^{\circ}$ triggering focus movements, and all elements will remain in the scope of the unary existential quantifier (all new information). On the other hand, in adjunct or argument focalizations, the quantifier selected will be a binary one (maybe better understood as an iota-quantifier than as an existential one, itself selected by a $\mathrm{Foc}^{\circ}$ (see more on this in Irurtzun (2005c)). Thus, in out-of-the-blue constructions, the linear order of the elements will be the following one (again, assuming a case-checking displacement of the object to Spec- $\nu \mathrm{P})$ :

$$
\text { T-S-O- } v-\mathrm{V}
$$

\footnotetext{
${ }^{25}$ See Grohmann (2000) and Platzack (2001) for discussion on the different functions of the $v \mathrm{P}$, TP and CP domains.

${ }^{26}$ As said before, in order to get the V2 effects of long-distance movements we would have to assume that the affixation applies before copy-deletion.
} 
If, as suggested, PF lowering applies rendering $[\mathrm{V}+v+\mathrm{T}]$ at the right edge of the string and then the T-affixation takes place, the word ordering obtained will be the following:

$$
\mathrm{S}-\mathrm{O}-[\mathrm{V}+v+\mathrm{T}]
$$

Obviously, this stipulated affixal nature of tense is something that has to be proven, but at this stage, it seems to me to be a plausible hypothesis. In fact, certain positive polarity-marking constructions of Basque show this affixal nature of the $\mathrm{T}^{\mathrm{o}}$ head. For instance, in (52), where an emphatic affirmative morpheme 'ba' appears, the auxiliary necessarily appears attached to the morpheme 'ba' ( $c f$. Ortiz de Urbina (1989), Laka (1990)):

(52) Jon ba-da etorri. Jon ba-AUX come 'Jon has so arrived'

However, these issues deserve a much more specific investigation, studying crosslinguistic and dialectal variation as well as the patterns of T-to-C movements of Wh-constructions. The issue is open for further research.

\section{5-Summary and Conclusions}

In this article, I have explored the nature of focus from a minimalist perspective and looking closely at Basque data. In strict Bare Phrase Structure terms, I proposed an alternative and derivational approach to the focus structure based on a potentially multiple assignment of $[+\mathrm{F}]$ features to different lexical items. With them, the focus structure is constructed derivationally via merge in the narrow syntax. After arguing for a left peripheric approach to the syntax of focus, I analyze the derivational dynamics of the syntax-LF derivation proposing a direct and transparent interface. Thus, assuming the logical form representation in Herburger (2000) whereby the focus falls in the scope of a restricted quantification over events, I argued for a system where the syntax feeds the semantics via a direct mapping where the binary quantifier gets its scope in the course of derivation. This aim is approached adopting Hornstein \& Uriagereka's (2002) mechanism of 'reprojection' that allows a binary quantifier to reproject, thus extending its local domain to get its second argument. Some issues remain to be resolved; among them, the affixal nature of the tense or the timing of the reprojection. Issues that deserve a more specific analysis.

\section{REFERENCES:}

Arregi, K. 2003a. Focus on Basque Movements. PhD. Dissertation, MIT.

Arregi, K. 2003b. Clausal Pied-piping. In Natural Language Semantics 11: 115-143.

Arregi, K. 2005. Basque is Right-Headed. Talk delivered at the University of Deusto, Bilbao.

Artiagoitia, X. 2000. Hatsarreak eta parametroak lantzen, Vitoria-Gasteiz: Universityof the Basque Country \& Arabako Foru Aldundia.

Boeckx, C. and Stjepanović S., 2001. Head-ing Toward PF. In Linguistic Inquiry 32 (2): 
345-355.

Bošković, Ž. 1999. On Multiple Feature Checking: Multiple Wh-fronting and Multiple Head Movement. In S. Epstein and N. Hornstein (eds.), Working Minimalism, 159-187. Cambridge MA: MIT Press.

Bošković, Ž. 2001. On the Syntax-Phonology Interface: Cliticization and Related Phenomena. Amsterdam: Elsevier Science.

Brody, M. 1990. Some Remarks on the Focus Field in Hungarian. UCL Working Papers in Linguistics 2, pp. 201-225.

Chomsky, N. 1995a. Bare Phrase Structure. In Government and Binding Theory and The Minimalist Program, G. Webelhuth (ed.), 383-420. Oxford: Blackwell.

Chomsky, N. 1995b. The Minimalist Program, Cambridge MA: MIT Press.

Chomsky, N. 2000a. New Horizons in the study of Language and Mind, Cambridge: Cambridge University Press.

Chomsky, N. 2000b. Minimalist Inquiries: The Framework. In Step by Step: Essays in Minimalist Syntax in Honor of Howard Lasnik, R. Martin, D. Michaels and J. Uriagereka (eds.), 89-155. Cambridge MA: MIT Press.

Chomsky, N. 2001. Derivation by Phase. In Ken Hale: A Life in Language, M. Kenstowicz (ed.), 1-52. Cambridge MA: MIT Press.

Davidson, D. 1967. The Logical Form of Action Sentences. In The Logic of Decision and Action, N. Rescher (ed.), Pittsburgh: University of Pittsburgh Press. [Reprinted in D. Davidson, 2001, Essays on Actions and Events, 105-122. New York NY: Oxford University Press].

Demirdache, H. and Uribe-Etxebarria, M. 2001. The primitives of temporal relations. In Step by Step: Essays on Minimalist Syntax in Honor of Howard Lasnik, R. Martin, D. Michaels, and J. Uriagereka (eds.), 157-186. Cambridge, MA: MIT Press.

Dominguez, L. 2004. Mapping Focus: The Syntax and Prosody of Focus in Spanish, $\mathrm{PhD}$. Dissertation, Boston University.

Elordieta, A. 2001. Verb Movement and Constituent Permutation in Basque, PhD. Dissertation, Leiden University.

Eguzkitza, A. 1986. Topics in the Syntax of Basque and Romance, PhD. Dissertation, University of California Los Angeles.

Grohmann, K. 2000. Prolific Peripheries: A Radical View From The Left. PhD. Dissertation, University of Maryland.

Halle, M. and Vergnaud, J-R. 1987. An Essay on Stress, Cambridge MA: MIT Press.

Herburger, E., 1998, Presupposition vs. Assertion; A Davidsonian Account. In UMOP 21: Proceedings of the Workshop on Focus, E. Benedicto, M. Romero and S. Tomioka (eds.), 125-141, Amherst MA: GLSA.

Herburger, E. 2000. What Counts: Focus and Quantification, Cambridge MA: MIT Press.

Higginbotham, J. 1985. On Semantics, Linguistic Inquiry 16 (4), 547-593.

Higginbotham, J. 2002. Why is Sequence of Tense Obligatory? In Logical Form and Language, G. Preyer and G. Peter (eds.), 207-227, Oxford: OUP.

Hornstein, N. and Uriagereka, J. 1999. Labels and Projections: A Note on the Syntax of Quantifiers. University of Maryland Working Papers in Linguistics 8, 249-270.

Hornstein, N. and Uriagereka, J. 2002. Reprojections. In Derivation and Explanation in the Minimalist Program, S. Epstein and T. D. Seely (eds.), 107-132. Malden MA and Oxford: Blackwell. 
Horvath, J. 1995. Structural Focus, Structural Case and the Notion of FeatureAssignment. In Discourse Configurational Languages, K. É. Kiss (ed.), 28-64. New York NY: Oxford University Press,

Hualde, J. I. and Ortiz de Urbina, J. 2003. A Grammar of Basque, Berlin: Mouton de Gruyter.

Irurtzun, A. 2003. A Derivational Approach to the Focus Structure. Manuscript, University of the Basque Country.

Irurtzun, A. 2005a. Reprojection \& Spell Out (or Vice-versa). Paper presented at the $X V$. Colloquium on Generative Grammar, Universitat de Barcelona, Barcelona.

Irurtzun, A. 2005b. Structure and Derivation of Split Focalization. In C. Umbach and C. von Heusinger (eds.), Proceedings of the ESSLLI Workshop on Discourse Domains \& Information Structure, 21-33.

Irurtzun, A. 2005c (in progress), The Grammar of Focus at the Interfaces, PhD. Dissertation, University of the Basque Country.

Irurtzun, A. and U. Etxeberria. 2004. Prosodic features with semantic interpretation. In Proceedings of JEL 2004 [Domain[e]s], O. Crouzet, H. Demirdache and S. Wauquier-Gravelines (eds.), 95-101. Nantes: AAI.

Jeong, Y. 2003. Multiple Wh-Fronting in Basque. Manuscript, University of Maryland.

Kratzer, A. 1996. Severing the External Argument from its Verb. In Phrase Structure and the Lexicon, J. Rooryck and L. Zaring (eds.), 109-139. Dordrecht: Kluwer.

Laka, I. 1990. Negation in Syntax: On the Nature of Functional Categories and Projections, PhD. Dissertation: MIT.

Laka, I. and Uriagereka, J. 1987. Barriers for Basque and Vice-Versa. In Proceedings of NELS 17, J. McDonough and B. Phunkett (eds.), 394-408. Amherst MA: GLSA.

Larson, R. 1991. The Projection of DP (and DegP). Manuscript, State University of New York at Stony Brook.

Larson, R. and Segal G. 1995. Knowledge of Meaning: An Introduction to Semantic Theory, Cambdrigde MA and London: MIT Press.

Merchant, J. 2004. Fragments and Ellipsis, Linguistics and Philosophy 27, 661-738.

Neeleman, A. and Reinhart, T. 1998. Scrambling and the PF Interface. In The Projection of Arguments; Lexical and Compositional Factors, M. Butt and W. Geuder (eds.), Stanford: CSLI Publications.

Ortiz de Urbina, J. 1983. Empty Categories and Focus in Basque. Studies in the Linguistic Sciences 13 (1), 133-156.

Ortiz de Urbina, J. 1989. Some Parameters in the Grammar of Basque, Dordrecht: Foris.

Ortiz de Urbina, J. 1993. Feature Percolation and Clausal Pied-piping. In Generative Studies in Basque Linguistics, J. I. Hualde and J. Ortiz de Urbina (eds.), Amsterdam: John Benjamins.

Ortiz de Urbina, J. 1995. Residual Verb First and Verb Second in Basque. In K. É. Kiss (ed.), Discourse Configurational Languages, 99-121, New York NY: Oxford University Press.

Ortiz de Urbina, J. 1999. Focus in Basque. In The Grammar of Focus, G. Rebuschi and L. Tuller (eds.), 311-334. Amsterdam: John Benjamins.

Ortiz de Urbina, J. 2003. Focus of Correction and Remnant Movement in Basque. In Erramu Boneta: A Festschrift for Rudolph P.G. De Rijk, J. Lakarra and X. Artiagoitia (eds.), Donostia: ASJU.

Parsons, T. 1991. Events in the Semantics of English, Cambridge (MA): MIT Press.

Platzack, Ch. 2001. Multiple Interfaces. In Cognitive Interfaces: Constraints on Linking Cognitive Information, U. Nikkane and E. van der Zee (eds.), 21-53. Oxford: 
Oxford University Press.

Rizzi, L. 1997. The fine structure of the left periphery. In L. Haegeman (ed.), Elements of Grammar, 281-337. Dordrecht: Kluwer.

Rooth, M. 1996. Focus. In The Handbook of Contemporary Semantic Theory, Sh. Lappin (ed.), Oxford: Blackwell.

Rooth, M. 1985. Association with Focus. PhD. Dissertation: University of Massachusetts at Amherst.

Rooth, M. 1992. A Theory of Focus Interpretation. Natural Language Semantics 1, 75116.

Schwarzschild, R. 1999. Giveness, AvoidF and Other Constraints in the Placement of Accent. Natural Language Semantics 17, 141-177.

Selkirk, E. 1995. Sentence prosody: Intonation, stress and phrasing. In The Handbook of Phonological Theory, J. Goldsmith (ed.), 550-569. Oxford: Blackwell.

Stowell, T. 1996. The phrase structure of tense. In Phrase Structure and the Lexicon, J. Rooryck and L. Zaring (eds.), 277-291. Dordrecht: Kluwer.

Uribe-Etxebarria, M. 2002. Wh in Situ and Masked Movement. In P. Pica and J. Rooryck (eds.), Linguistic Variation Yearbook 2, 217-257. Amsterdam: John Benjamins.

Uriagereka, J. 1999. Minimal Restrictions on Basque Movements. Natural Language and Linguistic Theory 17, 403-444. 